\title{
Gastrointestinal Stromal Tumor of Uncertain Malignant Potential
}

National Cancer Institute

\section{Source}

National Cancer Institute. Gastrointestinal Stromal Tumor of Uncertain Malignant

Potential. NCI Thesaurus. Code C54000.

A gastrointestinal stromal tumor that is characterized by a maximum diameter greater than $5 \mathrm{~cm}$ and equal or less than $10 \mathrm{~cm}$ (gastric localization), or greater than $2 \mathrm{~cm}$ and equal or less than $5 \mathrm{~cm}$ (intestinal localization) and no more than 5 mitotic figures per 50 high power fields. 